The two groups described above comprise a large proportion of the total and are easily distinguishable, but a certain number of cases in which both sets of symptoms are present to a variable extent offer some difficulty in diagnosis. We have to remember, however, that a person already suffering from an anxiety state may sustain concussion, and the contused person may develop some of the indications of the excessive fear reaction now to be considered.

\section{Influence of Fear}

I have so far spoken of " neuroses" in rather general terms, but there is one condition presenting a very definite picture which calls for detailed consideration It was shown by a large proportion, certainly not less than twothirds, of the cases classed as neuroses, and it was exhibited equally by men and women. These people start off at once by describing the terror they feel as soon as they hear an air-raid warning or gunfire. They begin to shake; some feel sick-" my stomach turns over" is a frequent description-and some even vomit; others have an immediate urge to micturate, and some have attacks of hyperidrosis. They cannot go on with their occupations; some feel impelled to rush out into the street; others run to the nearest shelter. At night they lie awake listening for warnings. Apart from these attacks of terror they have no complaints. Under examination they may show a tremor of the hands and eyelids and a somewhat quickened pulse.

Many of these people have led strenuous lives, often following occupations demanding judgment and " nerve," and no evidence of a neurotic tendency can be found in their personal histories. Their occupations have included lorrydriving and bus-driving, steel-erecting, tunnelling, platelaying, shunting, etc., and important clerical and administrative work. The women have brought up families, run businesses, and held responsible jobs. They have carried on at their work until the incident occurred which affected them, and some express their profound shame at finding themselves in their present state. Here are two typical instances:

A man, married, with four children, served in France, Egypt, and Gallipoli in the last war. On discharge with the rank of sergeant he became a park-keeper in a London park and subsequently head park-keeper. He had a considerable staff under him and had important A.R.P. duties in the park, which he discharged satisfactorily until one night when a bomb fell near but did not physically hurt him. Since that date he has been unable to go on with his work as he cannot control his terror during air raids.

Another mań served in France in the last war and had a good record. For twenty years he was a London bus-driver. In January of last year bombs fell near him, and he saw another bus wrecked and the driver blown ta pieces. He cannot now drive in London, and has been placed in a quiet outlying district; but whenever he hears a warning he must go at once to the nearest urinal, and sometimes wets his clothes.

These people feel sure that they would be all right if they were transferred to a safe district, and there is every reason to believe that they will again become normal citizens after the war.

I do not think this condition should be regarded as a neurosis at all. It has not the deep-seated foundations of an anxiety state and is simply an accentuation of the normal response to threat of danger. The reaction caused by a physiological stimulus which is excessive or prolonged is apt to be re-evoked when the stimulus is repeated in much milder form or even when there is merely a threat of such repetition. Examples are not rare in compensation claims. A familiar instance is afforded by the workman who once having had a serious fall is afraid to work at a height again. A youth who rode a carrier cycle in the City recovered completely from a bad accident, with the exception that he dared not ride again in crowded traffic.
Many persons are familiar with the condition in a minor form; speaking of a terrifying experience, they will say, " It makes me shudder to think of it again." Looking back, we can see now that many of the cases described. as "shell-shock" in the last war fell into this category. These symptoms are really in the nature of conditioned reflexes, and we can postulate no more about their aetiology than that those who display them have a rather greater susceptibility to the fear stimulus than their fellow-mena remark, however, which might be made about every form of disease. To describe this condition as anxiety neurosis, as ordinarily understood, is to suggest for it an aetiology for the existence of which there is no evidence. We require a term which shall simply define the condition without making any suggestion as to its fundamental origin, and none of our present names meet this need. "Commotional shock " and " emotional shock," terms used by Mott in the last war, have been recently revived; but the former seems to me to amount to concussion, and the latter to be our old friend " traumatic neurasthenia" under a new name. All these words carry implications with them, just as did " shell-shock." It would simplify the problem of handling these cases if they were lifted entirely out of the category of the neuroses; but this can never be done so long as they bear a designation indicating a neurotic origin. I have been accustomed to describe the condition in reports as " exaggerated fear reaction," which leaves the question of the aetiology entirely untouched; but a Greek cloak is kinder, and I suggest " hyperphobosis "* instead. The condition is not new. Job is our exemplar of withstanding adversity, yet he too felt it, and described it in the words: "In thoughts from the visions of the night, when deep sleep falleth upon men, Fear came upon me, and trembling, which made all my bones to shake. Then a spirit passed before my face; the hair of my flesh stood up." (Job iv, 13.)

REFEIENCE

Symonds, C. P. (1941). Injuries of the Skull, Brain, and Spinal Cord, ed. S. Brock, p. 96, Bailliere, London.

\section{SULPHONAMIDE TREATMENT OF HYPOPYON ULGER OF THE CORNEA}

BY

\section{LLOYD JOHNSTONE, M.C., M.D., D.O.} Honorary Surgeon, Worcester City and County Eye Hospital

The sulphonamide group of drugs have found a place in ocular therapeutics in this country, particularly in the treatment of ophthalmia neonatorum. Bellows and Chinn (1939) demonstrated that sulphanilamide penetrates to the ocular fiuids and tissues in suitable and efficient therapeutic concentration when given by mouth, but not when applied topically. Luo and P'an (1940) obtained quite different results when they experimented on human eyes. Concentration in the aqueous after instilling $1 \%$ sulphanilamide was roughly the same as after oral administration. After applying the drug in powdered form the concentration in the aqueous was from five to eight times as great.

The present article is the record of a clinical experiment directed against a particularly destructive corneal condition-hypopyon ulcer. Bacause the pneumococcus is often the organism involved in the condition sulphapyridine was chosen as the chief though not the only weapon. The experiment began in June, 1939, with the use of sulphapyridine eye-drops as a $0.07 \%$ solution in saline isotonic with the lacrimal secretion.

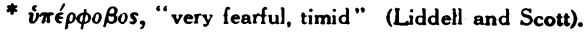


The results were encouraging without being phenomenal. They were a little better than those obtained with the usual antiseptics or optochin and in a parallel series of cases treated by older methods. No eyes were lost either in experimental cases or in controls, except those that had been severely burned by molten metal. The cases treated with sulphapyridine drops had the advantage of quicker recovery and less dense scarring of the cornea. Several of the control cases failed to clear up or recurred, and were inally cured by administering sulphapyridine drops, in one case assisted by subconjunctival injection of the same solution. In a proportion of the cases sulphapyridine has been given orally instead of or in addition to the drops.

During the last few months a number of really severe cases have appeared, and it became evident that only by frequent instillation of the drops could the condition bo prevented from deteriorating. A continuous drip was thought to be necessary to effect a cure, and this led to the use of sulphapyridine powder just as one uses calomel powder in phlyctenular ulcers. By this means 3 cases with purulent regurgitation from tear sacs were successfully healed; the tear sacs were subsequently removed-2 after healing of the cornea and 1 while healing was in progress.

Subconjunctivai injections of soluseptasine $(10 \%)$ have been given in a small number of cases in which therc was no apparent discharge from the eye and conjunctival redness was moderate. One case-a typical serpiginous ulcer in a coal-miner, with early collection of pus in the anterior chamber-was given such an injection and the patient was allowed to go home - a risk one could never have taken in the past. Two days later the hypopyon had cleared and the ulcer had healed.

\section{Accessory Forms of Treatment}

In addition to the sulphonamide every case has had atropine drops and some form of cautery of the ulcer. It is true that some cases are cured by these means alone, but many eyes have been lost when these forms of treatment, aided by every art and antiseptic, have been carried out. It may be possible to omit cautery of the ulcer when using a sulphonamide : that and several other permutations and combinations of sulphonamide treatment remain to be tried.

\section{Suggested Routine Treatment}

In the light of experience so far gained the following is suggested as an outline of treatment, to be modified as further experiment may indicate :

1. The patient should as a rule be admitted to hospital.

2. A smear and culture are taken.

3. Atropine is an essential part of treatment, and cautery may prove to be so (see above)

4. In the absence of purulent discharge, possibly even with slight discharge, a subconjunctival injection of two or three depots of soluseptasine $(10 \%)$ or sulphapyridine $(0.07 \%)$, about five minims to each depot, should be given. Possibly stronger solutions of sulphapyridine may yet become available.

5 . When the organism is known the appropriate sulphonamide treatment should be chosen. For the pneumococcus, sulphapyridine powder should be dusted lightly over the cornea three times a day. For a streptococcus, sulphanilamide powder may be used or soluseptasine continued as drops or by subconjunctival injection. For Staphylococcus aureus, sulphathiazole would seem to be the appropriate drug. It has been used in the form of drops in this experiment as $0.1 \%$ solution in $1.4 \%$ saline, but no definite opinion can yet be offered regarding its superiority over sulphapyridine.

Fine powder (200-mesh) causes no discomfort to the patient, though considerable conjunctival redness arises. So far the practice has been to precede the dusting by one drop of $1 \%$ decicaine. Any discomfort complained of has been relieved by removal of the pad and bandagc. There is no need for this dressing unless the cornea erodes deeply and requires external pressure.

The total number of cases treated, apart from controls, is 41. Details of cases and comparative tables have not been given, as it is felt that brevity is preferable at the present time.

The two kinds of drops and the sulphapyridine powder were supplied by May and Baker, Ltd., to whom my thanks are tendered. My thanks are also due to the ophthalmic housesurgeons and nursing staff at the Guest Hospital and Eye Infirmary, Dudley, and to the matron and nurses at the Worcester City and County Eye Hospital.

REFERENCES

Bellows, J. G. and Chinn, H. (1939). J. Amer. med. Ass... 112, 2023.

Luo, T. H., and P'an, S. Y. (1940). Chin. med. J., 58, i67:

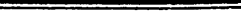

THE GALGULATION AND PRESCRIBING OF INFANTS' FEEDS*

\section{THE NEONATAL PERIOD : PRAGTICAL POINTS IN THE REGULATION OF FEEDS IN MATERNITY HOSPITALS AND HOMES}

BY

HELEN M. M. MACKAY, M.D., F.R.C.P. Physician for Diseases of the Newborn to the Mothers' Hospital; Member of the Staff of the Medical Research Council

Many experienced sisters in maternity hospitals deal very successfully with feeding problems without the aid of any schedule of feeding, but their experience has to be bought at the price of many mistakes, and is not easily passed on to others unless it can be formulated in some general principles. At a time when many new maternity homes have been established in reception areas, and large numbers of newborn babies must be coped with by midwives with occasional help from a general practitioner, some practical suggestions may be helpful.

\section{Routine of Feeding}

Full-term babies are best put to the breast as soon as the mother has had some hours' rest after her laboursay about six hours after birth-and thereafter fed at regular intervals. But there is no object in keeping the baby at the breast for more than a few minutes at a time until the milk has "come in." Three-hourly feeding, giving both breasts at each feed until lactation is fully established, probably suits a larger proportion of newborn babies than a four-hourly routine, but against this must be set the greater amount of rest allowed to the mother by a four-hour interval. In any case nearly all normal babies can be started on five feeds in the day at fourhourly intervals before they are a month old. The time spent over a feed should never exceed thirty minutes and should seldom exceed twenty minutes. Many strong babies will soon take all they need in eight to ten minutes. Long feeds exhaust baby and mother and generally lead to an inadequate intake.

A common cause of lethargy and failure to suck is a subnormal temperature. When a lethargic baby develops slight oedema one can be fairly sure the temperature has fallen to a low level, perhaps on the previous day; moreover, if a baby shows little or no loss in weight after birth he should be examined for oedema. The keeping of a temperature chart for each baby in the maternity ward is strongly advised. Underfeeding, too, is often a cause of lethargy and poor sucking, and hence may establish a vicious circle; but every lethargic baby merits 